\title{
Developing and sustaining a Community of Practice through Twitter for work-based learning
}

\section{Julie Attenborough, Rachael-Anne Knight, Judy Brook}

$10.1136 /$ eb-2018-102981

School of Health Sciences, University of London, London, UK

Correspondence to: Ms Julie Attenborough, City, University of London, UK; J.A. Attenborough@city.ac.uk

\section{Background}

In the UK, the introduction of the apprenticeship levy in April 2016 and nursing associate role in January 2017 presented new opportunities to further develop the clinical workplace as a learning environment for employees. ${ }^{1}$ City, University of London, in collaboration with London South Bank University, is leading an 18-month project, funded by Health Education England to explore and address factors in preparing the clinical environment for work-based learning (WBL). The project supports key stakeholders to form a community of practice $\left(\mathrm{COP}^{2}\right)$ to identify and solve problems, while simultaneously creating guidelines and resources for best practice in local implementation of supervision and WBL. The project connects academics and clinicians through social media, in particular Twitter. ${ }^{3-5}$

In 2018, we hosted five Twitter chats, curated by academic and clinical staff. Twitter chat topics were chosen following initial consultation with COP members and focused on the following areas (a summary of the questions is available at https://twitter.com/CityJoolz/ status/1016342539064967168):

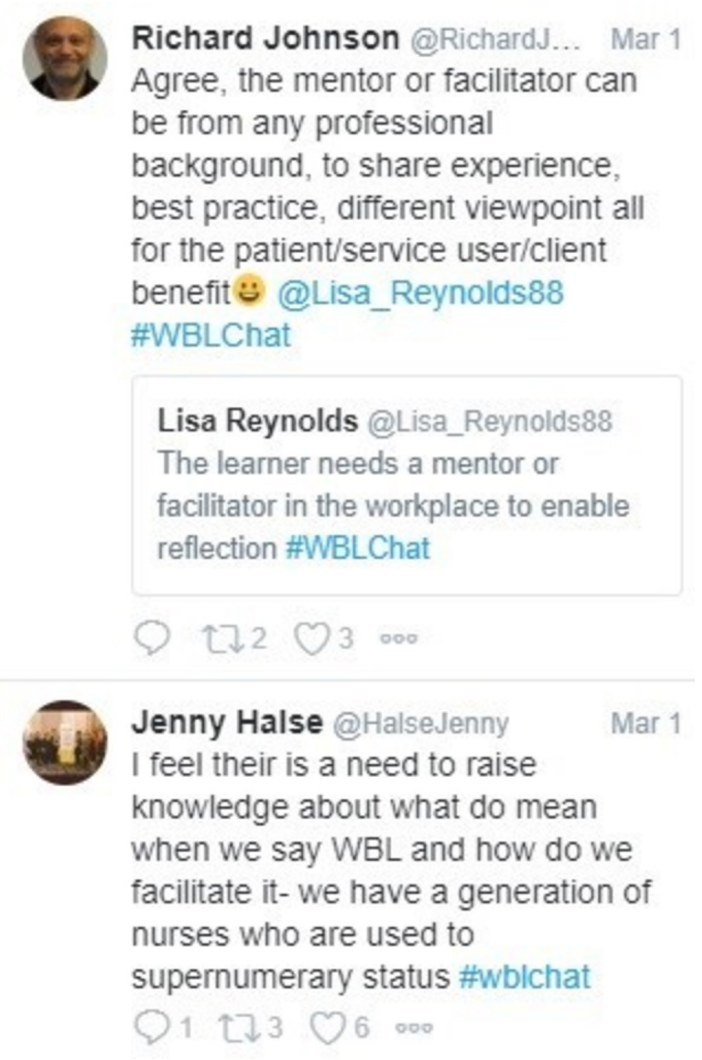

Figure 1 Importance of facilitating workbased learning (WBL) through mentorship and facilitation.

\section{Twitter chat topics}

1. What is WBL and what do we need to effectively deliver it?

2. Storytelling for WBL (recontextualised learning).

3. Developing a learning culture.

4. Cognitive apprenticeships.

5. Parity of esteem between work-based and traditional learning.

\section{Themes (\#WBLChat)}

\section{Chat 1}

Four themes dominated the initial Twitter chat: refocusing learning, student/learner support, organisational culture, and capacity and structure for work-based learning. The majority of participants felt that WBL was a refocusing of learning; a way of integrating theory and practice. Participants supported the need to move away from traditional delivery of education and perceived the benefit of work-based learning. However, clinicians expressed concern about their capacity to deliver this, while endorsing an organisational culture that values and enables WBL.

Participants were acutely aware of a lack of time, staff and an established framework for WBL. Many felt that mentors or facilitators need particular training to facilitate WBL. Participants identified the potential for using the professional background of mentors and supervisors to share experiences, best practice and different viewpoints (figure 1).

\section{Chat 2}

This focused on the role of storytelling by practitioners to support WBL and introduced some of the concepts first discussed by Donald Schon ${ }^{6}$ including how professional thinking is developed and how professionals think in practice. The dominating themes were use of storytelling as a teaching tool, how storytelling helps to build relationships, the use of storytelling as reflection and the effectiveness of storytelling.

The majority of the participants found storytelling a useful tool in linking theory and practice, using their experiences as examples. By sharing their experiences, educators make a crucial contact as human beings, capable of making mistakes; helping students reflect on their actions. Participants questioned how the successfulness of using storytelling could be measured and formalised into the learning process to ensure it is beneficial and effective, highlighting the danger of using it as a scare tactic. There was also a suggestion even if a story might be considered 'dull', it can indirectly aid the student, as the process of storytelling aids relationship-building. In this chat, participants spontaneously shared their resources about storytelling through weblinks.

\section{Chat 3}

The third Twitter chat focused on the benefits of the surrounding workplace culture in creating good learning 
Tom Starr-Marshall @TStarr... Jun 18 Replying to @WBL_SP

I think it's worth putting in effort to

focus very early in a course on

building individual reflection

frameworks that work personally for

each individual. This way it is

embedded by the time student

reaches placement and they can do it

without support/high workload

\#WBLChat

$\left.Q_{1} \uparrow\right\urcorner_{1} \smile_{3} 00$

Q1)

Rachael-Anne Knight @r_a... Jun 18

Replying to @TStarrMarshall @WBL_SP

Sounds brilliant. How do you get

learner to build their own reflection

framework? \#WBLChat

Q 1 ใ\1 O2 000

Figure 2 Importance of embedding personal frameworks of reflection.

experiences. Participants tweeted about the challenges of creating a learning environment that encouraged active engagement in a multitude of learning opportunities, observing the necessity for mentors/supervisors to be proactively and purposely involved to engage learners. For the first time, participants discussed the importance of collaborative leadership alongside engagement of the whole team embracing the learner and increasing competence, extending the scope of practice.

Reflective feedback was discussed in all four chats, but was especially relevant and dominant here, along with mutual respect. Participants revisited sharing of stories and recontextualised learning.

\section{Chat 4}

The fourth chat focused on cognitive apprenticeships. ${ }^{7}$ A YouTube video and relevant papers were shared before the chat to explain the concept and the curator used a Twitter poll to establish awareness. Four themes dominated the discussion: the importance of reflection, supporting learners in practice, balancing the dual roles of teacher and work colleague and developing thinking skills in solution-focussed learners. One participant revealed negative connotations of reflection, also described by Hannigan. ${ }^{9}$ Participants called for the building of individual reflection frameworks (figure 2), the use of modelling and scaffolding to support learning in the workplace, the use of coaching and the flattening of hierarchies. Once again, storytelling emerged as an important technique.

\section{Chat 5}

The fifth chat addressed parity of esteem between WBL and learning that is primarily based in higher education institutions. The four themes dominating the discussion were how different learning needs may be met by different types of education, the potential for lack of understanding of how WBL operates, the opportunities provided by work-based learning and possible improvements to parity of esteem. Participants discussed the importance of the prevailing narrative surrounding WBL, for example, how ensuring 'degree apprenticeships' are named in full may make their parity with other degrees more obvious.

\section{Conclusion}

This series of Twitter chats has allowed us to build a community of practice, including academics, healthcare professionals and students, as an alternative to face-to-face interactions, which can be difficult to organise due to time and workload constraints. The chats have provided excellent suggestions and ideas for further exploration in future chats in order to continue to promote WBL.

Competing interests None declared.

Patient consent Not required.

Provenance and peer review Commissioned; internally peer reviewed.

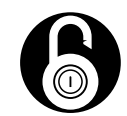

\section{OPEN ACCESS}

Open access This is an open access article distributed in accordance with the Creative Commons Attribution Non Commercial (CC BY-NC 4.0) license, which permits others to distribute, remix, adapt, build upon this work non-commercially, and license their derivative works on different terms, provided the original work is properly cited, appropriate credit is given, any changes made indicated, and the use is non-commercial. See: http://creativecommons.org/licenses/by-nc/4.0/.

( A Author(s) (or their employer(s)) 2018. Re-use permitted under CC BY-NC. No commercial re-use. See rights and permissions. Published by BMJ.

\section{References}

1. Halse J, Reynolds L, Attenborough J. Creating new roles in healthcare: lessons from the literature. Nursing Times 2018;114:34-7.

2. Lave J, Wenger E. Situated learning: legitimate peripheral participation in communities of practice. New York: Cambridge University Press, 1993.

3. Lewis B, Rush D. Experience of developing Twitter-based communities of practice in higher education. Research in Learning Technology 2013;21:1-13.

4. Megele C. Theorizing Twitter chat. Journal of Perspectives in Applied Academic Practice 2014;2.

5. Budak C, Agrawal R. On participation in group chats on Twitter. Proceedings of the 22nd international conference on World Wide Web, 2013:165-76.

6. Schon DA. The reflective practitioner: how professionals think in action. Temple Smith; New York: Basic Books, 1983.

7. Woolley NN, Jarvis Y. Situated cognition and cognitive apprenticeship: a model for teaching and learning clinical skills in a technologically rich and authentic learning environment. Nurse Educ Today 2007;27:73-9.

8. Collins A, Brown J, Newman S. Cognitive apprenticeship: teaching the crafts of reading, writing and mathematics. In: Resnick L, ed. Knowing, learning, and instruction: essays in honour of Robert Glaser. Hillsdale, NJ: Lawrence Erlbaum Associates, 1989:453-94.

9. Hannigan B. A discussion of the strengths and weaknesses of 'reflection' in nursing practice and education. J Clin Nurs 2001;10:278-83. 